Article

\title{
Estimating Land Development Time Lags in China Using DMSP/OLS Nighttime Light Image
}

\author{
Li Zhang ${ }^{1,2}$, Ge Qu ${ }^{1,3}$ and Wen Wang ${ }^{1, *}$
}

1 Center for Spatial Information, School of Environment and Natural Resources, Renmin University of China, Beijing 100872, China; E-Mails: li.zhang@kcl.ac.uk(L.Z.); qqugge@163.com(G.Q.)

2 Department of Geography, King's Building, King's College London, Strand, London WC2R 2LS, UK

3 China Land Surveying and Planning Institute, Beijing 100035, China

* Author to whom correspondence should be addressed; E-Mail: wen_wang2000@ hotmail.com; Tel.: +86-10-8889-3061.

Academic Editors: Christopher D. Elvidge, Heiko Balzter and Prasad S. Thenkabail

Received: 30 June 2014 / Accepted: 6 January 2015 / Published: 14 January 2015

\begin{abstract}
The Chinese real estate industry has experienced rapid growth since China's economic reform. Along with a booming industry, a third of purchased lands were left undeveloped in the last decade. Knowledge of real estate development time lags between land being purchased and property being occupied can enable policymakers to produce more effective policies and regulations to guide the real estate industry and sustain economic development and social welfare. This paper presents an innovative method to estimate provincial land development time lags in China using DMSP/OLS NTL imagery and real estate statistical data. The results showed that real estate development time lag was common in China during 2000-2010. More than half of the study sites showed development time lags of three years or longer. An Increment of Developed Pixels (IDP) index was established to outline yearly land development completions in China between 2000 and 2010. A Comprehensive Real Estate Price Index (CREPI) was created to explore the causes of the time lags. A strong and positive correlation was found between the real estate development time lags and CREPI values (with $r=0.619, n=31, p<0.0005$ ). The results indicated that the land development time lag during the study period was positively correlated to the activity of the local real estate market, the price trend of land and housing properties, and the local economic situation. The results also proved that with the support of statistical data the
\end{abstract}


DMSP/OLS NTL image could offer an economically efficient and reliable solution to estimate the time lag of real estate development.

Keywords: DMSP/OLS nighttime light image; real estate market; time lags; land development

\section{Introduction}

The sustained rapid economic growth of China has fuelled its real estate industry since the 1980s [1,2]. The industry has now entered a period of steady increase after an initial period of rapid growth and has become one of the key industries in the Chinese economy [3]. Despite the prosperous appearance of the real estate market, problems remain [2]. Rapid urbanization has left large amounts of land undeveloped after the prescribed period is due. According to the National Bureau of Statistics of China, 3.3 billion $\mathrm{m}^{2}$ of land was purchased by real estate developers between 2000 and 2009, but only 2.1 billion $\mathrm{m}^{2}$ of it completed development. The fact that over a third of the purchased land was left undeveloped might produce a number of negative social impacts, e.g., potential lack of housing for local populations, vacant lands, and soaring land and house prices [4].

Present studies on the delay of land development are mostly concentrated on its presence, cause, impact, and potential countermeasures from a macro point of view. White [5] and Keuschnigg et al. [6] pointed out that by hoarding land the developers were not just trying to avoid a possible shortage of land caused by housing demand exceeding market supply in the future, but frequently pursuing huge profits from a rapid increase of land and house prices. An analysis by Raymond [7] showed that developers' land banks tend to decrease when the market interest rates increase, implying that land banking behaviors are likely related to the economic situation. Land banking as a business strategy has special importance to giant enterprises due to their monopolistic positions in the market. Clapp et al. [8] treated the starting time of a development real estate as a Real Option (RO) in their study and found a positive relationship between the RO values of the development and the fluctuation of housing prices. Zhu's study [4] suggested that imperfect and ineffective laws and government regulations indirectly impel real estate developers to hoard land in China. Although extensive qualitative research has been carried out on land banking behaviors, little has been done quantitatively. The knowledge of the development time lags and their regional differences may provide the administrators and policymakers of both the central and local governments with a valuable reference point for understanding the real estate market and therefore producing effective policies and regulations to tackle existing and potential problems.

Remote sensing technology can provide real-time low-cost data for scientific research and has offered a new angle for social and economic studies [9-11]. Among the various types of remote sensing data, the Defense Meteorological Satellite Program's Operational Linescan System (DMSP/OLS) Nighttime Light (NTL) image has proven to be a favorable source for monitoring anthropogenic activities [12]. DMSP/OLS NTL data have been collected by the U.S. Air Force Defense Meteorological Satellite Program (DMSP) Operational Linescan System (OLS) since the 1970s [13]. With a unique low-light detection function at night, OLS can measure radiances down to $10^{-9}$ watts $/ \mathrm{cm}^{2} / \mathrm{sr}$. It can capture various types of radiation generated by human beings on the earth's surface including city light, heavily lit fishing boats, gas flares, etc. It can even detect light from traffic in streets and light from scattered human settlements $[14,15]$. 
The sharp contrast between the lit-up areas and the dark background of the NTL images opens up a panorama of socioeconomic activities of the earth in the night-time [16]. NTL data has been widely applied in various aspects of social science research such as socioeconomic development [9,12,17], energy consumption [11,18,19], light pollution [20], forest fire monitoring [21-23], snow cover detection [24], war studies [25], etc. Great achievements have been made in urban studies using NTL data in the last few decades. As early as 1978, Croft [26] first proposed that DMSP/OLS NTL data could be used to extract built-up areas. Later, Imhoff et al. [27] managed to separate urban and nonurban land cover types of the whole USA using NTL data at good confidence using a threshold method. Henderson et al. [28] then compared DMSP/OLS stable lights data with high-resolution Landsat TM image and delimited different levels of urbanization and economic development boundaries in several cities. To improve the continuity and comparability of DMSP/OLS NTL data, Liu et al. [29] developed a new data pre-processing method to monitor the urban expansion dynamic in China between 1992 and 2008, based on the previous work of Yuan et al. [30] that estimated the territorial development intensity (TDI) of China at provincial scale using NTL data. In the same year, Yao et al. [31] successfully analyzed the economic bubbles in the Chinese real estate market by comparing the Digital Number (DN) values of NTL data with the house prices in 50 Chinese cities. A number of research papers have proved that multi-temporal NTL data could effectively portray the dynamic processes of urbanization (e.g., Ma et al. [32]; Sutton [33]). Previous research has proved that NTL data can be a viable tool for various urban studies, such as urbanization progress, human activity boundaries delineation, and land development level determination. However, no research has been done on the time lag of urban land development.

In this paper, we present a unique method to estimate the time lags of land development in China at a provincial level over a recent decade (2000-2010) by combining an Increment of Developed Pixels (IDP) index extracted from NTL data with other social ancillary statistics data, and analyze the regional differences of urban development in China.

\section{Data and Methods}

\subsection{Study Area}

In total, 31 provinces/municipalities in mainland China were covered by this research (Figure 1). China has started commercializing homes since the start of its economic reform in 1978. Before that, all land was publicly owned and the free right of using land could not be transferred to others. The permission to make land transactions, granted by the Chinese constitution in 1988, started the privatization of housing in China [34]. Since then, the lease of land can be purchased for development, living on, or for other purposes, although the land itself cannot be privately owned. As a result, the real estate industry in China has experienced a steady growth alongside the sustained national economic development [1] and become one of the key industries in the national economy [3]. Since 1998, a number of policies in favor of the real estate market were released by the central government and boosted the whole industry. For example, the State Department issued "A notice on further changes to urban housing policy reform to speed up housing construction" in 1998. This has formed a new policy framework for the Chinese housing supply system. Within this framework, the old welfare-oriented public housing system has been removed and a new economically affordable housing system was establishing. Since then, the major housing suppliers 
in China were changed to real estate developers. Both investment and turnover of the market started soaring and housing prices experienced a sharp and steady rise [35]. The firm rise of house prices in China, shown in Figure 2, gives a good example of this rapid development.

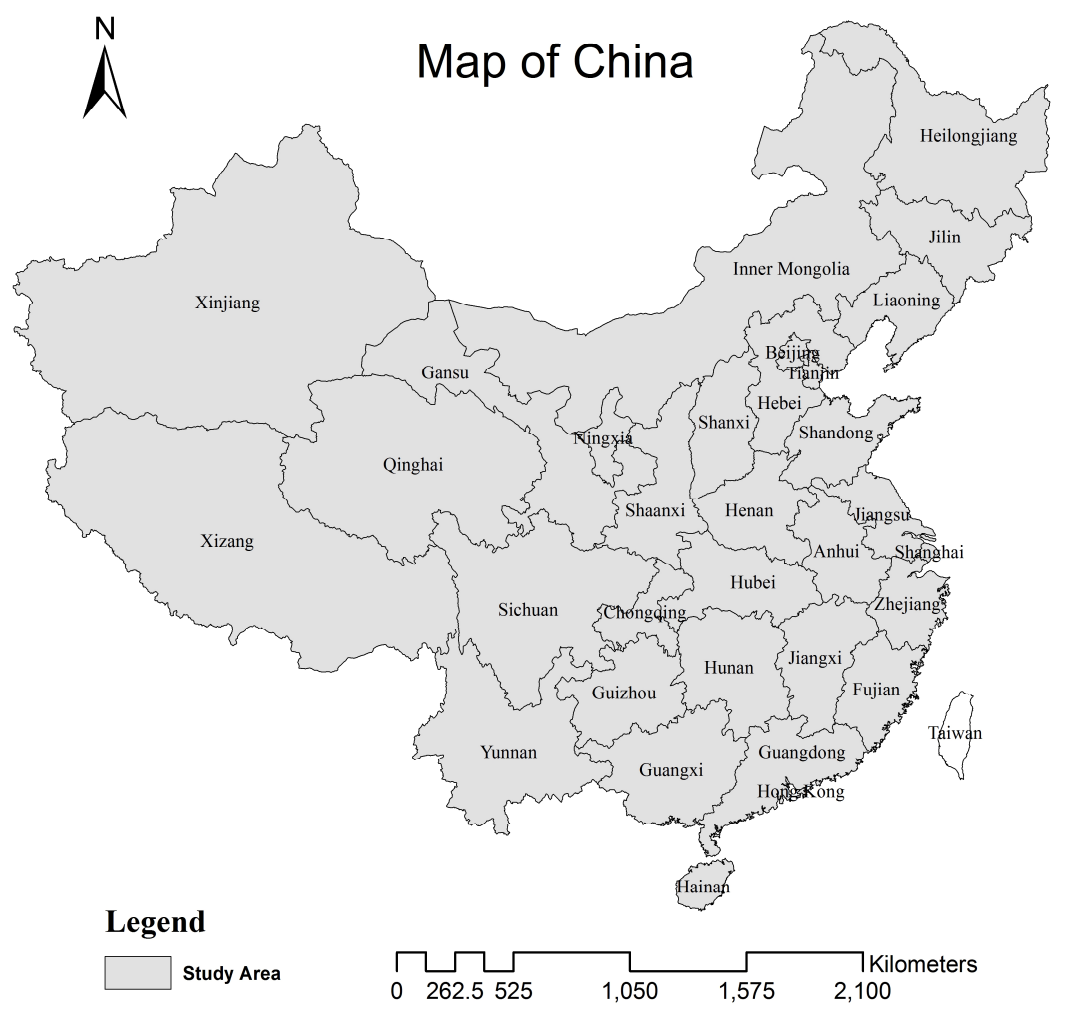

Figure 1. Map of the study area-31 provinces/municipalities in China.

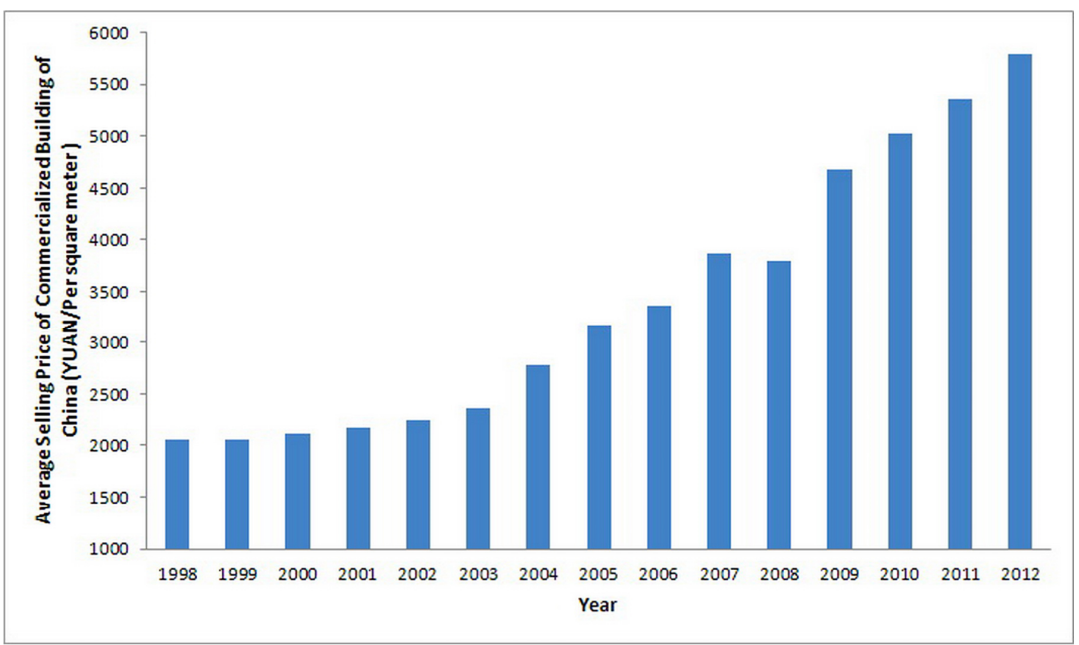

Figure 2. The average selling price of commodity housing in China between 1998 and 2012 [35].

Different from many other countries, there are two types of housing in the Chinese real estate market, namely economically affordable housing and commodity housing. These were defined by Chinese law in 1998. Local governments decide the price of economically affordable housing before these housing projects begin. The price of these houses is usually $3 \%-5 \%$ above their total costs and this type of housing 
is usually targeted at families with low incomes. The price of commodity housing is determined by the market. The data from the Chinese National Bureau of Statistics showed a sharp decline of the market share of affordable housing since it reached its peak at $17 \%$ in 1999 and decreased rapidly to below $6 \%$ since 2005. Commodity housing now dominates the real estate industry in China. Due to the fact that all land in China is owned by the State, the real estate market is affected by the amount of land released by local government. On the other hand, local government expects to achieve a balanced economic development and social welfare by guiding the real estate market through the amount of land sold each year. With the boom in the real estate industry, a large amount of land has been left vacant due to the desire for substantial potential profits by the developers. Not knowing the scale of vacant land, local governments may lose control of the real estate market and potential negative impacts from land hoarding may occur.

\subsection{DMSP/OLS NTL Data}

Nineteen sets of $1 \mathrm{~km}^{2}$ (32 arc seconds) spatial resolution cloud-free DMSP/OLS NTL version 4 data from the National Oceanic and Atmospheric Administration's (NOAA) National Geophysical Data Center (NGDC) were selected for this study. The selected data were captured by four different DMSP satellites in the period between 2000 and 2010 (Table 1), covering an area from -180 to 180 degrees longitude and -65 to 75 degrees latitude. Each set of data was a composite of all available archived DMSP/OLS images from the same calendar year. When there were two satellites collecting data in the same year, two data composites were obtained.

Table 1. A list of satellites used to produce annual NTL data.

\begin{tabular}{lllll}
\hline Year & \multicolumn{3}{c}{ Satellite } \\
\hline 2000 & F14 & F15 & & \\
2001 & F14 & F15 & & \\
2002 & F14 & F15 & & \\
2003 & F14 & F15 & & \\
2004 & & F15 & F16 & \\
2005 & & F15 & F16 & \\
2006 & & F15 & F16 & \\
2007 & & F15 & F16 & \\
2008 & & & F16 & \\
2009 & & & F16 & \\
2010 & & & & F18 \\
\hline
\end{tabular}

An example of the original 2010 global DMSP/OLS NTL image is shown in Figure 3. The brightness of each pixel in the image is encoded with a Digital Number (DN) ranging from 0 to 63. Each DN indicates the percent frequency of light from the ground detected by the sensor within a set of cloud-free observations. Higher DN values associate with more intense light. The annual composite DMSP/OLS data have been pre-processed to remove sunlight, glare, moonlight, clouds, auroras, light features, and ephemeral events such as fires. The background noise has also been identified and set to zero value. 


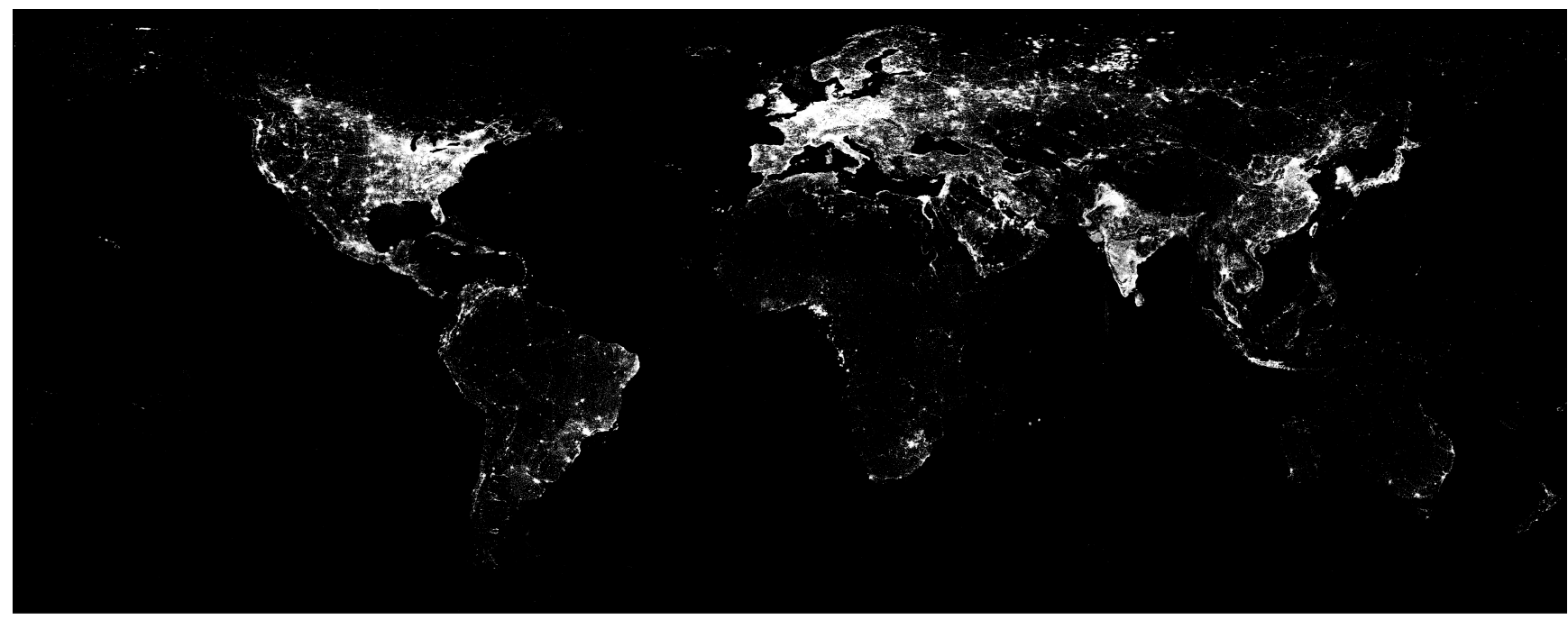

Figure 3. Global DMSP/OLS nighttime light in 2010 (by NGDC).

\subsection{Socioeconomic Statistical Data and Fundamental Geographic Data}

Annual socioeconomic statistics data are good indicators for the real estate market. A set of data, including Area of Land purchased (ALP), Cost of Land Purchased (CLP), Area of commercialized Housing Sold (AHS), and Average Selling Price (ASP) of commercialized building between 2000 and 2010, and Built-up Areas in 2000, were obtained from the National Bureau of Statistics of China and the China Real Estate Statistics Yearbook. In the China Real Estate Statistics Yearbook, the Area of Land purchased (ALP) is defined as the area of a plot of land, of which the usufruct are purchased by an enterprise for real estate development through bidding, auctioning, or listing from the State in a specific year. Area of commercialized Housing Sold (AHS) refers to the area of both residential and commercial housing sold in a period for which statistics had been recorded. It includes the floor space of both off-plan housing and completed housing apartments. The Average Selling Price (ASP) of commercialized building refers to the average selling price of a commercialized building per square meter. Both "commercialized housing" and "commercialized building" here refers to the term "commodity housing."

An up-to-date Chinese administrative boundary vector map was acquired from the National Geomatics Centre of China, and transformed into Albers Projection (Beijing54_Albers_Equal_Area central meridian $=105$ standard parallel $=27,45)$ using ESRI ArcGIS 9.3.

\subsection{DMSP/OLS NTL Data Pre-Processing}

All 19 sets of DMSP/OLS NTL images of China spanning 11 years from 2000 to 2010 were extracted from the DMSP/OLS NTL global data using the Chinese administrative boundary map and re-projected into Albers Projection. As described in Section 2.2, different DMSP satellite sensors were involved in the selected data. Due to a number of reasons-e.g., lack of onboard calibration and strict inter-calibration, different sensors, and sensor degradation - a large number of unstable pixels in the NTL data formed a major barrier to its application in long-term temporal analysis [10,29]. Figure 4 demonstrates the basic statistics of the NTL data for China in 2000-2010. Clear disagreements between different satellites can easily be seen from the graphs in Figure 4a,b. For example, there were two sets of NTL data for China in 2004. With the same ground coverage, satellite F15 had recorded 1,201,983 
pixels with positive $\mathrm{DN}$ value while satellite F16 had recorded 1,462,722, showing a 22\% gap (Figure 4a). The NTL image taken by satellite F15 in 2007 had a total Digital Number (DN) value of $11,622,479$; however, this value decreased to $9,760,726$ in 2008 , contrary to both previous research findings and the general knowledge on economic growth and development (Figure $4 \mathrm{~b}$ ). Therefore the original data needed to be calibrated before use. The data pre-processing procedure in this study included three steps: (1) inter-calibration of annual image composites; (2) production of intra-annual composition; and (3) inter-annual corrections [29].
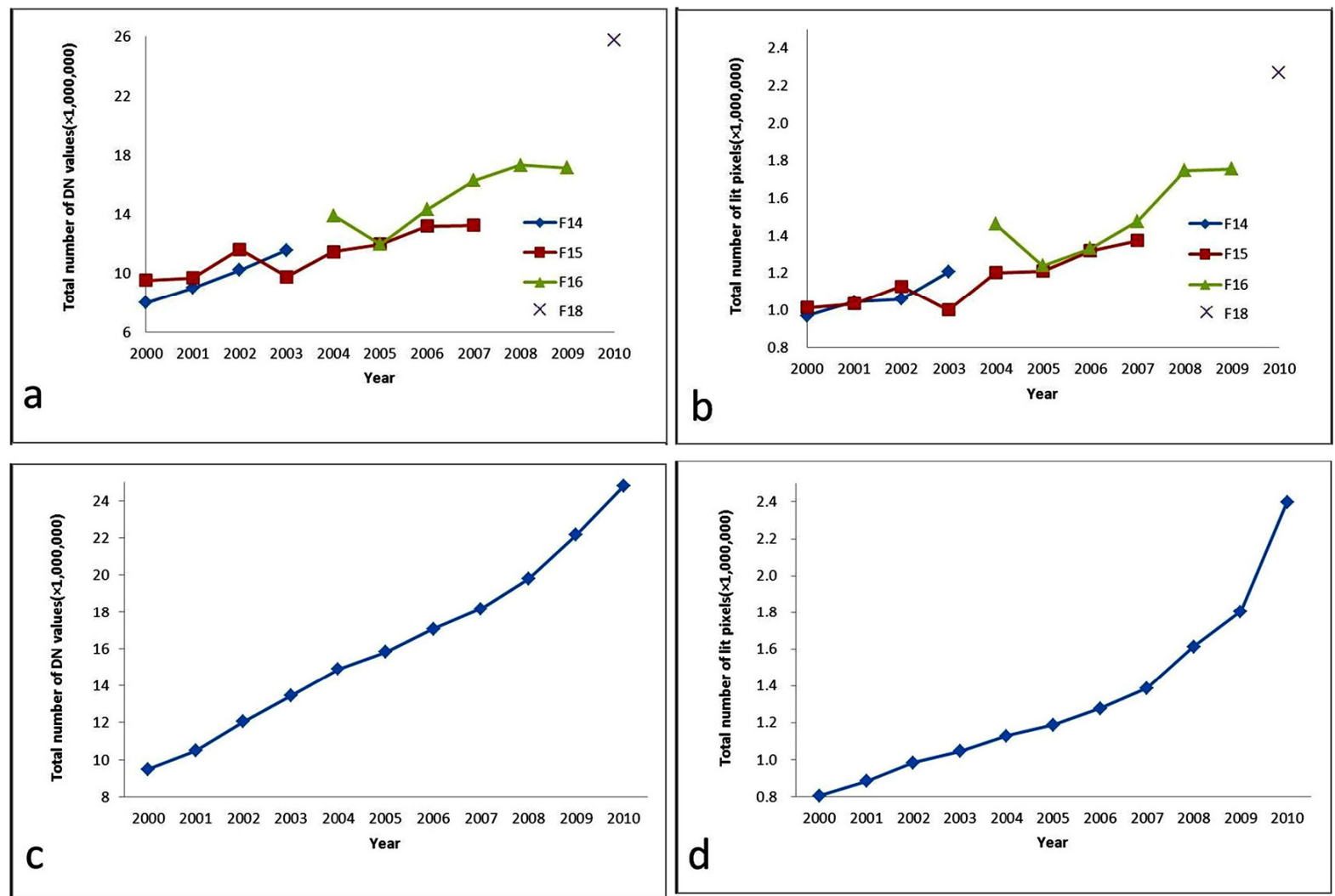

Figure 4. Basic statistics of the NTL China data between 2000 and 2010, with (a,b) before calibration; (c,d) after calibration.

\subsubsection{Inter-Calibration of Annual Composites}

As there is no on-board calibration for DMSP/OLS data, Elvidge et al. [14] developed an empirical procedure to inter-calibrate individual composites (1994-2008). They found the Sicily F121999 image the best reference for inter-calibration after examining numerous candidate calibration areas around the world. Their approach significantly improved the comparability and continuity of NTL data. This unique second order regression model for inter-calibrating the annual NTL products is given below [14]:

$$
D N_{\text {adjusted }}=C_{0}+C_{1} \times D N+C_{2} \times D N^{2}
$$

where $\mathrm{C}_{0}, \mathrm{C}_{1}$, and $\mathrm{C}_{2}$ are coefficients. In this study, we have adopted the above method and its coefficients for the data obtained between 2000 and 2008. We also used F121999 Sicily image as the calibration reference to calculate the coefficients for F162009 and F182010 data. The coefficients for 
F162009 and F182010 composites are $(0.3158,1.0861,-0.0017)$ and $(-0.0138,0.6159,0.0056)$, respectively.

\subsubsection{Intra-Annual Composition}

In this study, eight out of 11 years had a pair of images produced by two different satellites (see Table 1). To make full use of the available data and minimize the uncertainty caused by different satellite sensors, intra-annual composites were produced by averaging the DN values of each pair of composites for those having two sets of images [29].

\subsubsection{Inter-Annual Corrections}

China is currently experiencing rapid urban expansion. More agricultural land is becoming developed around the country each year. We assumed that once a pixel in the NTL image was lit up (DN > 0), it would not disappear or become dimmer in any following years [29,36,37]. As a result, the number of lit pixels and the sum of the DN values in an image in each following year should only stay unchanged or become larger. Based on this assumption, the unstable pixels in the images could be removed using Equation (2) [29]. If a NTL pixel's DN value was greater than 0 in one year but equaled 0 in the preceding and following years, or vice versa, this pixel was thought to be "unstable" and needed correction (see Equation (2)).

$$
D N_{(n)}=\left\{\begin{aligned}
0 \text { if } D N_{(n-1)} & =0 \& D N_{(n+1)}=0 \& D N_{(n)}>0 \\
\frac{\left[D N_{(n+1)}+D N_{(n-1)}\right]}{2} \text { if } D N_{(n-1)}>0 \& D N_{(n+1)}>0 \& D N_{(n)} & =0
\end{aligned}\right.
$$

where $D N$ is the digital number value of a pixel in the NTL image and $n$ is the study year $(n=2001$, 2002, .., 2010).

To ensure that the DN values in an earlier image do not exceed those of a later one, all pixels in the images were examined and modified using Equation (3) after unstable pixels were corrected.

$$
D N=\left\{\begin{array}{c}
0 \text { if } D N_{(n+1)}=0 \\
D N_{(n-1)} \text { if } D N_{(n+1)}>0 \& D N_{(n-1)}>D N_{(n)} \quad(\mathrm{n}=2001, \ldots 2010) \\
D N_{(n)} \text { otherwise }
\end{array}\right.
$$

The quality of the DMSP/OLS NTL data showed a significant improvement after correction (see Figure 4c,d).

\subsection{Extraction of Built-Up Areas}

The threshold method is a common technique to extract built-up areas from a DMSP/OLS NTL satellite image [33] that can overcome the "over-glow" problems caused by overestimation of lit areas [38]. The most common threshold definition approaches include expert knowledge [26], outlier value detection [38], ancillary statistic data [37], or comparison study [28] approaches. Shu et al. [39] proved that an ancillary statistic data method worked well in the circumstances in China. Considering its convenience and accuracy, the ancillary statistic data method was selected to extract built-up areas in each province/municipality in this study. The development levels of different regions vary dramatically in 
China. For example, a large gap between eastern and western China can easily be observed in the image. Hence, unique thresholds (see Section 3.1, Table 2) were defined for each province in this study to reflect the socioeconomic differences and ensure the accuracy of the study when using the statistical ancillary data method [28,37]. Pixels with DN values above threshold aggregate together and outline the developed built-up areas of each administrative unit in the image.

The ancillary statistic data method [37] includes three steps: (1) In each year, we assume that the maximum DN value of a specific province is the threshold $\left(\mathrm{DN}_{\mathrm{t}}\right)$ and calculate the total area of pixels $\left(\mathrm{S}_{\mathrm{t}}\right)$ with their NDs equal to DNt; (2) $\mathrm{S}_{\mathrm{t}}$ is compared with the built-up area statistics for each province in 2000 published by the National Bureau of Statistics of China $\left(S_{2000}\right)$. Usually $S_{t}$ from maximum DN is much smaller than $S_{2000}$; (3) DN $\mathrm{DN}_{\mathrm{t}}$ is adjusted downwards to calculate a new $S_{t}$, until $S_{t}$ is closest to $S_{2000}$. The DN that produced the best matching $S_{t}$ is selected as the threshold for this specific province in this specific year.

\subsection{Increment of Developed Pixels (IDP)}

The dynamics of urbanization in China during the study period could be detected by overlapping the extracted urban maps of the study sites. In order to capture these dynamics quantitatively, an Increment of Developed Pixels (IDP) index was introduced to the study. IDP was defined as the number of urban pixels increased in the DMSP/OLS image in a specific year (Equation (4)):

$$
I D P_{n}=D P_{n}-D P_{n-1} ;(\mathrm{n}=2001, \ldots 2010)
$$

where DPn and DPn-1 are numbers of pixels that are classified as built-up areas in a province/municipality in a specific year and its previous year, respectively; $n$ is the specific study year; and $n-1$ is the previous year.

This index could define the area of freshly developed land after being released by developers and then occupied by consumers in this specific study year.

\subsection{Estimation of Land Development Time Lags}

In China, the normal procedure for a piece of land to become developed into residential, commercial, or industrial properties includes the following four stages (Figure 5): (1) acquisition of a land usufruct by the developer; (2) construction of building(s) for residential or commercial purposes on the land; (3) properties sold to real estate consumers; and (4) occupation of the properties. The time lag between a piece of land being purchased and being occupied by human beings as a residential home or a non-residential purpose building was defined as land development time lag. The time lag between stages 1 and 3 was caused by the developer, thus was called developer time lag here. Similarly, the time lag in the last stage was caused by consumer decorating and preparing for occupation, therefore it was seen as a consumer time lag.

In the NTL images, the development stages could be seen as a gradual increase of DN values of specific pixels from 0 to the defined urban threshold. In other words, this progress is a gradual light up of some pixels in the NTL image. By measuring the light up progress, the average land development time lags or delays between the land usufruct acquisition stage and property occupation stage in each province/municipality could be calculated. We hypothesized that once the property on a piece of land 
was occupied, it could be detected by a DMSP/OLS image at night. We also hypothesized that a piece of land would always light up after being detected as occupied by people in the NTL image.

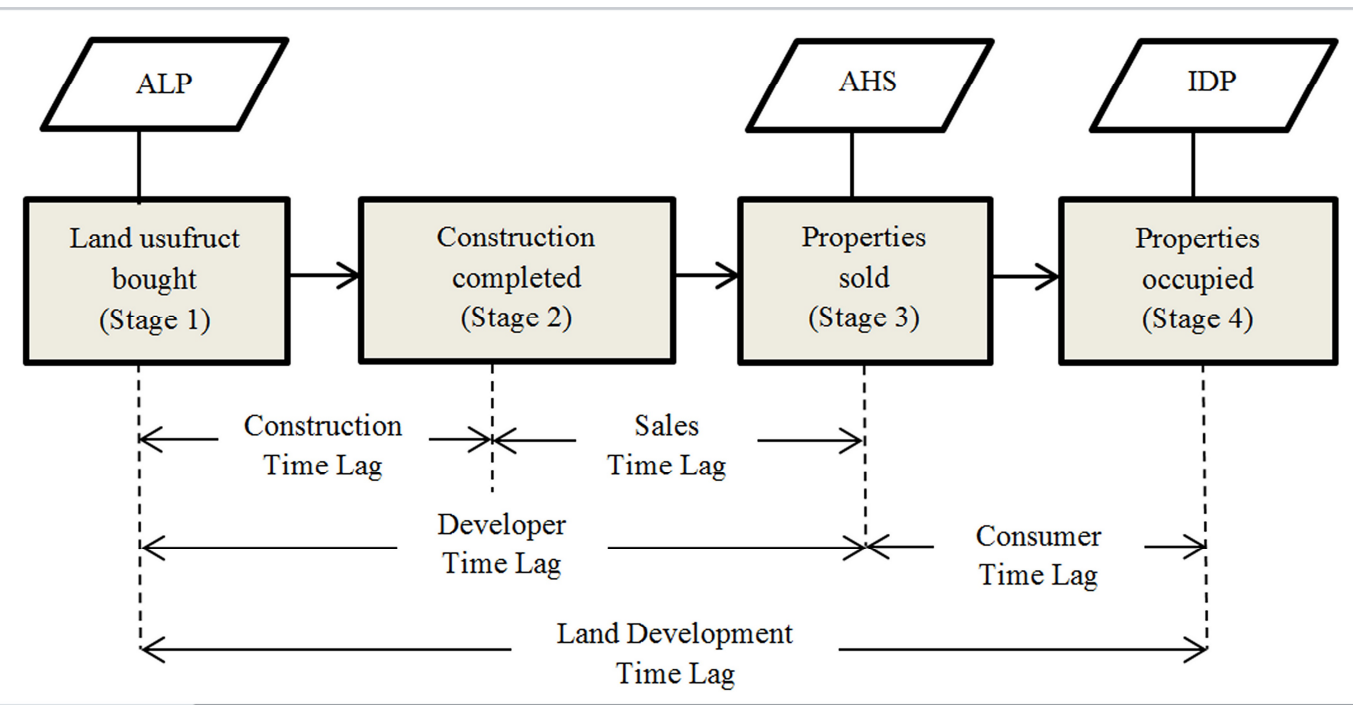

Figure 5. The procedure of real estate land development in China and the potential time lags at each stage of the development.

A cross-correlation coefficients method was used to estimate the average land development time lags. Different from correlation analysis method, cross-correlation analysis measures the correlation quality of the asynchronism of two variables to reveal the lead or lag relationship between them [40,41]. The two variables included in this method were the Area of Land Purchased (ALP) and the Increment of Developed pixels (IDP) each year during the study period. The cross-correlation coefficient $r(l)$ between them indicated the correlation quality of the two variables at lag or at lead for a certain period $(l)$. It can be calculated using Equation (5):

$$
r(l)=\frac{\frac{1}{n} \sum_{i=1}^{n+l}\left(x_{i}-\bar{x}\right)\left(y_{i-l}-\bar{y}\right)}{s_{x} s_{y}}(l=0,1,2, \ldots \ldots)
$$

where $x$ is IDP; $y$ is ALP; $i$ refers to a specific study year; and $l$ is the land development time lag period (unit: year) between the purchase of land and the light up of the properties. According the land development process procedure, $x$ always happens behind y, therefore $l \geq 0 . S_{(x)}$ and $S_{(y)}$ are the standard deviations of $x$ and $y$, respectively, and $n$ is the length of the study period.

In Equation (5), if $y$ is the Area of Housing Sold (AHS) associated with the land development stage 3 (see Figure 5), the Developer Time Lag $\left(l_{d}\right)$ could also be calculated. Theoretically, the land development time lag $(l)$ should not be shorter than the developer time lag $\left(l_{d}\right)$, i.e. $l \geq l_{d}$, as the former has included the consumer time lag $\left(l_{c} \geq 0\right)$.

As the average home decorating time for a $150 \mathrm{~m}^{2}$ apartment in China is less than 1.5 months and people intend to rest the flat for 2-6 months before moving in to avoid possible harm from toxic construction materials, the consumer time lag is normally less than 1 year. In this study, we presume that home decorating time is negligible, therefore the developer time lag $\left(l_{d}\right)$ can be used as an approximate measure to assess the accuracy of the land development time lag $(l)$ results from the NTL image. When $l<l_{d}$, the value of developer time lag can be used as the adjusted land development time lag $\left(l_{a d}\right)$. 


\subsection{Comprehensive Real Estate Price Index (CREPI)}

To explore possible causes of real estate development time lags, a Comprehensive Real Estate Price Index (CREPI) was also introduced into this study. CREPI is a non-dimensionalized composite score index based on the Rate of Change in Housing Price (RCHP or $R_{H}$ ) and the Rate of Change in Land Price (RCLP or $R_{L}$ ) during the study period. RCHP and RCLP can be calculated using statistical records (2000-2010) for each province/municipality from the China Real Estate Statistics Yearbook, including the Average Selling Price (ASP) of commercialized building, the Area of Land purchased (ALP), and the Cost of Land Purchased (CLP). The non-dimensional method for calculating CREPI is given in Equation (6):

$$
C R E P I=0.5 \times\left(\frac{\overline{R_{H}}-\operatorname{Min}\left(R_{H}\right)}{\operatorname{Max}\left(R_{H}\right)-\operatorname{Min}\left(R_{H}\right)}\right)+0.5 \times\left(\frac{\overline{R_{L}}-\operatorname{Min}\left(R_{L}\right)}{\operatorname{Max}\left(R_{L}\right)-\operatorname{Min}\left(R_{L}\right)}\right)
$$

where $R_{H}$ is the rate of change in housing price and $R_{L}$ is the rate of change in land price.

\section{Results}

\subsection{Extraction Thresholds and Maps of Built-up Areas}

The optimal DN thresholds for each province, calculated using the statistical ancillary data method [37], are given in Table 2. Six provinces/municipalities—Beijing, Shanghai, Shandong, Tianjin, Jiangsu, and Guangdong — had very high values, close to the saturation value $(\mathrm{DN}=63)$. The statistics of the average provincial Annual Per Capita GDP during 2000-2010 had shown that these areas were more developed than the rest of China. On the contrary, underdeveloped areas such as Xizang, Hunan, Guizhou, and Jiangxi all displayed relatively low thresholds at nearly or below half of the thresholds of developed areas.

Table 2. DN thresholds for extracting built-up areas in each province/municipality.

\begin{tabular}{cccccc}
\hline Provinces & Threshold & Provinces & Threshold & Provinces & Threshold \\
\hline Beijing & 61 & Ningxia & 48 & Hainan & 36 \\
Shanghai & 59 & Inner Mongolia & 46 & Anhui & 35 \\
Shandong & 59 & Jilin & 46 & Chongqing & 35 \\
Tianjin & 58 & Heilongjiang & 45 & Hubei & 32 \\
Jiangsu & 57 & Henan & 44 & Sichuan & 32 \\
Guangdong & 57 & Qinghai & 44 & Xizang & 32 \\
Fujian & 51 & Xinjiang & 44 & Hunan & 28 \\
Hebei & 50 & Shaanxi & 42 & Guizhou & 26 \\
Shanxi & 49 & Yunnan & 41 & Jiangxi & 21 \\
Liaoning & 49 & Gansu & 41 & & \\
Zhejiang & 49 & Guangxi & 36 & & \\
\hline
\end{tabular}

A positive correlation $\left(R^{2}=0.565\right)$ was found between DN threshold and the 11-year average Annual Per Capita GDP (Figure 6). Developed provinces/municipalities tended to have higher thresholds than less developed regions. This result agreed with a previous study by Henderson et al. [28]. 


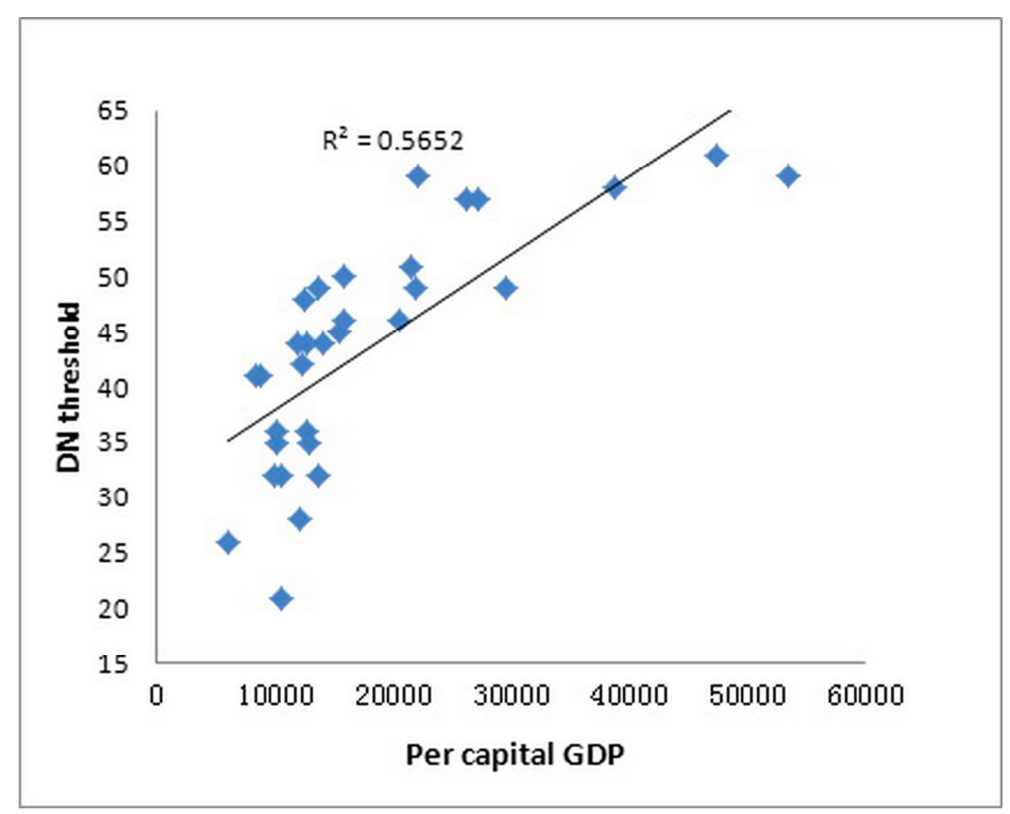

Figure 6. Relationship between the DN threshold of built-up areas and average provincial annual per capital GDP.

Figure 7 demonstrates a steady expansion of urban built-up areas in mainland China between 2000 and 2010. A clear regional pattern has been shown. More developed areas such as Beijing, Tianjin, the Yangtze River Delta region, and Guangdong in eastern China have displayed the strongest and quickest urban expansion. Strong economic growth in these areas has attracted a large immigrant population and as a result their built-up areas experienced faster and greater expansion. The Chinese national population census between 2000 and 2010 indicated that the resident population of Beijing and Tianjin municipalities increased from 23 million in 2000 to 32 million in 2010, with an increase rate of $37.9 \%$. Similarly, the residential population in Guangdong has experienced a rise from 86 million to 105 million, a 21.4\% rate. In less developed areas in central China, including Guizhou, Chongqing, Guangxi, Hunan, Hubei, Jiangxi, etc., less built-up area expansion can be observed due to most of their newly added population having migrated to more developed eastern regions for work opportunities. The national population census in these areas during this 11-year period remained almost unchanged (about 278 million). The built-up areas in these regions only displayed a very minor growth. Other areas such as Xizang and Qinghai in western China had experienced a population rise- $15.8 \%$ and $10 \%$, respectively_although the expansion of their built-up areas was not obvious due to their small original population in 2000 ( $0.6 \%$ of the Chinese population).

\subsection{Land Development Time Lags}

Table 3 shows the estimated land development time lags and developer time lags of the selected 31 provinces/municipalities in China during the study period, ranging from zero to five years. Nearly half of the provinces/municipalities had land development time lags one or two years longer than their developer time lags. Before introducing AHS for adjustment (see Section 2.7), 18 provinces/municipalities showed land development time lags of three years or longer. The results also showed that four provinces had one-year time lags and three provinces had no lags. After adjustment, two-thirds of 
provinces/municipalities showed a lag of three years or longer. Only two provinces showed one year or no lag-Qinghai and Ningxia, respectively; both were the most underdeveloped areas in China. The longest five-year lag period occurred in seven provinces/municipalities-Shanghai, Tianjin, Zhejiang, Shaanxi, Shanxi, Jiangxi, and Hubei-mainly concentrated in more developed eastern and central China. More than a third of the provinces/municipalities took four years to finish development and get properties occupied. All provinces with development lags of three years or less were in underdeveloped regions.
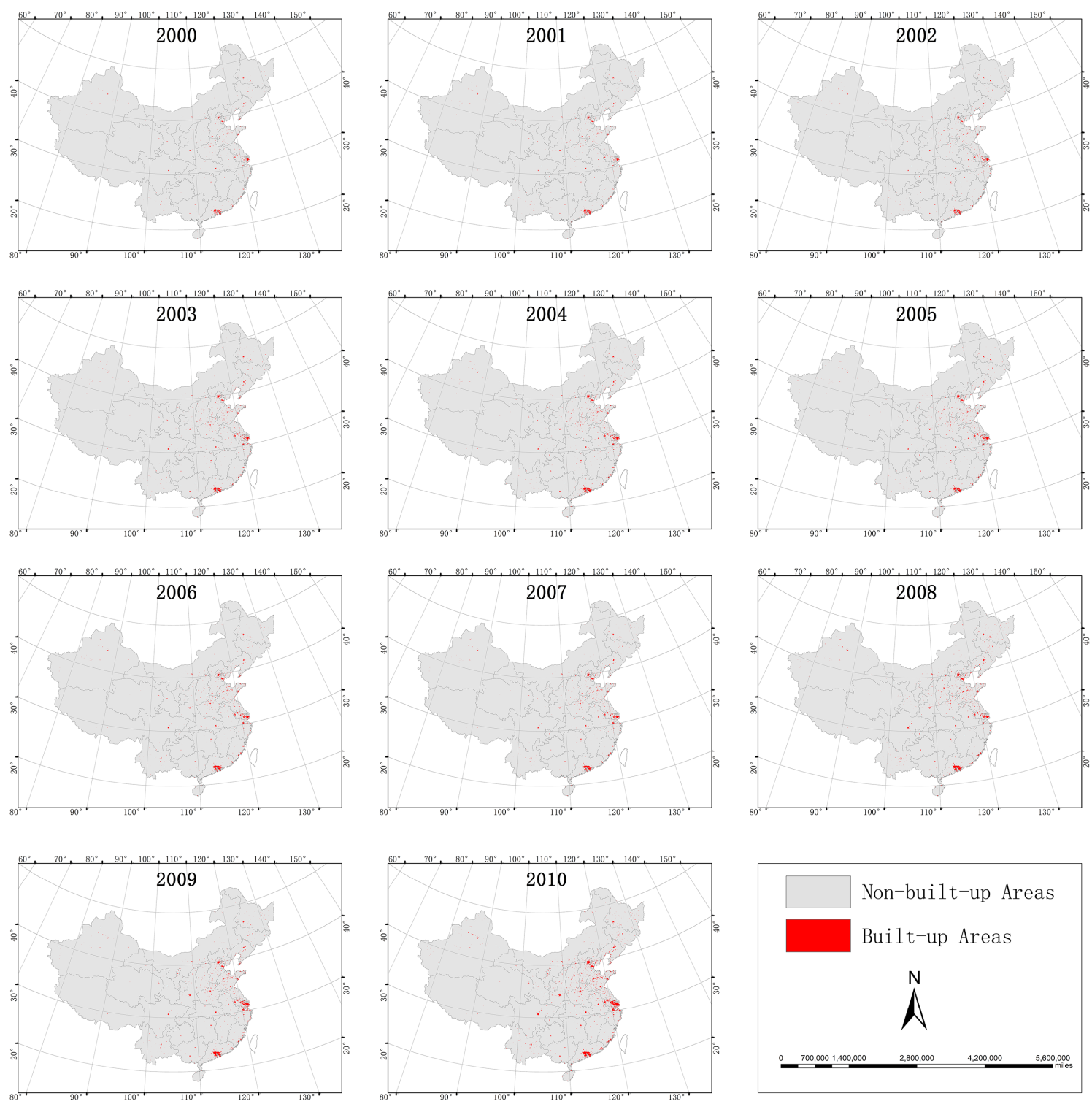

Figure 7. Maps of extracted built-up areas in the selected 31 provinces/municipalities between 2000 and 2010 in China.

In general, there was no major regional pattern of real estate development lags in China. The results implied that real estate development time lag was common in China during 2000-2010. The results also demonstrated that the length of real estate development of a region was related to its economic situation. 
The Maximum Cross-Correlation (MCC) coefficients between ALP, IDP, and AHS were also included in Table 3, with about $90 \%$ of provinces/municipalities having a value above 0.5 , which indicated high confidence in the time lag results.

Table 3. Land development time lags $(l)$, developer time lags $\left(l_{d}\right)$, and adjusted time lags $\left(l_{a d}\right)$ in 31 provinces/municipalities in China between 2000 and 2010.

\begin{tabular}{|c|c|c|c|c|c|c|}
\hline Provinces & $\begin{array}{l}\text { Time } \\
\text { Lags } \\
(l)\end{array}$ & $\begin{array}{c}\text { Developer } \\
\text { Time Lags } \\
\qquad\left(l_{d}\right) \\
\end{array}$ & $\begin{array}{c}\text { Adjusted } \\
\text { Time Lags } \\
\quad\left(l_{a d}\right) \\
\end{array}$ & $\begin{array}{c}\text { Max. Cross- } \\
\text { Correlation Coefficient } \\
\text { of ALP and IDP }\end{array}$ & $\begin{array}{c}\text { Max. Cross- } \\
\text { Correlation Coefficient of } \\
\text { ALP and AHS }\end{array}$ & $\begin{array}{c}\text { Per Capita } \\
\text { GDP in } 2000 \\
\text { (Chinese Yuan) }\end{array}$ \\
\hline Anhui & 3 & 2 & 3 & 0.63 & 0.89 & 4779 \\
\hline Beijing & 4 & 3 & 4 & 0.75 & 0.66 & 24,122 \\
\hline Chongqing & 4 & 3 & 4 & 0.46 & 0.68 & 5616 \\
\hline Fujian & 1 & 4 & 4 & 0.56 & 0.74 & 11,194 \\
\hline Gansu & 2 & 3 & 3 & 0.77 & 0.77 & 4129 \\
\hline Guangdong & 4 & 3 & 4 & 0.68 & 0.54 & 12,736 \\
\hline Guangxi & 4 & 3 & 4 & 0.72 & 0.92 & 4652 \\
\hline Guizhou & 3 & 3 & 3 & 0.65 & 0.71 & 2759 \\
\hline Hainan & 4 & 2 & 4 & 0.97 & 0.77 & 6798 \\
\hline Hebei & 2 & 2 & 2 & 0.79 & 0.94 & 7592 \\
\hline Heilongjiang & 4 & 2 & 4 & 0.78 & 0.95 & 8294 \\
\hline Henan & 1 & 2 & 2 & 0.26 & 0.93 & 5450 \\
\hline Hubei & 0 & 5 & 5 & 0.53 & 0.59 & 6293 \\
\hline Hunan & 4 & 2 & 4 & 0.51 & 0.73 & 5425 \\
\hline Jiangsu & 4 & 2 & 4 & 0.63 & 0.61 & 11,765 \\
\hline Jiangxi & 5 & 5 & 5 & 0.65 & 0.66 & 4851 \\
\hline Jilin & 2 & 2 & 2 & 0.89 & 0.92 & 7351 \\
\hline Liaoning & 2 & 2 & 2 & 0.87 & 0.93 & 11,177 \\
\hline Inner Mongolia & 3 & 2 & 3 & 0.96 & 0.97 & 6502 \\
\hline Ningxia & 0 & 0 & 0 & 0.81 & 0.78 & 5376 \\
\hline Qinghai & 1 & 1 & 1 & 0.85 & 0.63 & 5138 \\
\hline Shaanxi & 5 & 2 & 5 & 0.51 & 0.92 & 4968 \\
\hline Shandong & 1 & 4 & 4 & 0.49 & 0.48 & 9555 \\
\hline Shanghai & 5 & 3 & 5 & 0.76 & 0.5 & 30,047 \\
\hline Shanxi & 5 & 2 & 5 & 0.75 & 0.92 & 5722 \\
\hline Sichuan & 4 & 4 & 4 & 0.72 & 0.39 & 4956 \\
\hline Tianjin & 5 & 3 & 5 & 0.51 & 0.85 & 17,353 \\
\hline Xinjiang & 2 & 2 & 2 & 0.57 & 0.41 & 7372 \\
\hline Xizang & 4 & 3 & 4 & 0.70 & 0.52 & 4572 \\
\hline Yunnan & 2 & 2 & 2 & 0.71 & 0.91 & 4770 \\
\hline Zhejiang & 0 & 5 & 5 & 0.70 & 0.13 & 13,416 \\
\hline
\end{tabular}

\subsection{Rate of Change in Housing/Land Price}

Table 4 demonstrates the average annual Rate of Change in Housing Price (RCHP) / Land Price (RCLP) and their relationship to the land development time lags in 31 provinces/municipalities in China. It implies that the whole country experienced a noticeable rise in land and housing prices during the study period. 
The average annual price increase in housing and land prices across China were $11.1 \%$ and $20.9 \%$, respectively. Two-thirds of the provinces/municipalities had experienced $10 \%$ or more annual housing price inflation. Higher RCHPs are mostly concentrated in southeast coastal areas and other economically developed areas. The RCHP of Zhejiang, Shanghai, and Hainan (all coastal) had reached 15\% or above, implying sharp increases in housing prices in these regions and indicating vigorous real estate markets there during the study period. The lowest RCHP happened in Heilongjiang and Yunnan, both less developed; however, it still reached $6.1 \%$ and $7.9 \%$. The land price inflation in China was dramatic during the study period. Similar to housing price inflation, higher price rises happened mainly in more economically developed regions. More than a third of the provinces/municipalities had experienced an over one-quarter increase in RCLP. The two major municipalities, Beijing and Shanghai, had their RCLP exceed 36\% during the 10-year study period. Less developed Ningxia, Qinghai, and Heilongjiang had the lowest land price rise, but still had noticeable RCLPs of $5.7 \%, 6.8 \%$, and $7.5 \%$, respectively.

The Pearson Correlation Analysis method was used to test the relationships between RCHP, RCLP, and the adjusted development time lag. Statistically significant strong and positive correlations have been found between the time lag and both RCHP (with $r=0.569, n=31, p<0.001$ ) and RCLP (with $r=0.628$, $n=31, p<0.0005)$.

Table 4. The average annual Rate of Change in Housing Price (RCHP), Rate of Change in Land Price (RCLP), and Adjusted land development time lags $\left(l_{a d}\right)$ in 31 provinces/municipalities in China between 2000 and 2010.

\begin{tabular}{cccccccc}
\hline Provinces & RCHP & RCLP & Adjusted Time Lags & Provinces & RCHP & RCLP & Adjusted Time Lags \\
\hline Zhejiang & $16.9 \%$ & $27.0 \%$ & 5 & Guangxi & $9.4 \%$ & $15.8 \%$ & 4 \\
Shanghai & $15.0 \%$ & $36.7 \%$ & 5 & Guangdong & $8.8 \%$ & $15.2 \%$ & 4 \\
Tianjin & $13.5 \%$ & $25.6 \%$ & 5 & Heilongiiang & $7.9 \%$ & $7.5 \%$ & 4 \\
Jiangxi & $12.7 \%$ & $22.1 \%$ & 5 & Anhui & $13.4 \%$ & $25.6 \%$ & 3 \\
Shaanxi & $12.0 \%$ & $26.2 \%$ & 5 & Inner Mongolia & $12.0 \%$ & $15.5 \%$ & 3 \\
Shanxi & $11.6 \%$ & $19.7 \%$ & 5 & Guizhou & $10.2 \%$ & $23.9 \%$ & 3 \\
Hubei & $10.6 \%$ & $27.2 \%$ & 5 & Yunnan & $6.1 \%$ & $15.2 \%$ & 3 \\
Hainan & $16.0 \%$ & $23.4 \%$ & 4 & Jilin & $10.0 \%$ & $24.0 \%$ & 2 \\
Beijing & $13.7 \%$ & $36.4 \%$ & 4 & Hebei & $9.3 \%$ & $14.7 \%$ & 2 \\
Jiangsu & $13.5 \%$ & $29.2 \%$ & 4 & Henan & $9.2 \%$ & $15.3 \%$ & 2 \\
Chongqing & $12.2 \%$ & $28.3 \%$ & 4 & Gansu & $8.9 \%$ & $15.8 \%$ & 2 \\
Sichuan & $11.9 \%$ & $28.3 \%$ & 4 & Liaoning & $8.1 \%$ & $17.8 \%$ & 2 \\
Fujian & $11.6 \%$ & $25.6 \%$ & 4 & Xinjiang & $8.0 \%$ & $10.8 \%$ & 2 \\
Hunan & $11.3 \%$ & $22.1 \%$ & 4 & Qinghai & $9.3 \%$ & $6.8 \%$ & 1 \\
Shandong & $10.7 \%$ & $27.4 \%$ & 4 & Ningxia & $9.3 \%$ & $5.7 \%$ & 0 \\
Xizang & $10.4 \%$ & $12.2 \%$ & 4 & & & & \\
\hline
\end{tabular}

\subsection{Comprehensive Real Estate Price Index (CREPI)}

Table 5 displays the CREPI of each study site between 2000 and 2010. In this table, Shanghai, Beijing, Zhejiang, Hainan, and Jiangsu have very high CREPI values (>0.7). Except for Hainan, the other four provinces/municipalities were the most developed areas in China. Xinjiang, Qinghai, Yunnan, Ningxia, and Heilongjiang showed very low values $(<0.2)$, most of which were the poorest regions in the country. 
A Pearson Correlation Analysis has revealed that the adjusted development time lag had a strong and positive correlation with the CREPI index (with $r=0.619, n=31, p<0.0005$ ). The correlation was statistically significant.

Table 5. Provincial CREPI during study period in 2000-2010.

\begin{tabular}{cccccc}
\hline Provinces & CREPI & Provinces & CREPI & Provinces & CREPI \\
\hline Shanghai & 0.912 & Jiangxi & 0.570 & Hebei & 0.293 \\
Beijing & 0.847 & Shandong & 0.563 & Gansu & 0.293 \\
Zhejiang & 0.844 & Hubei & 0.555 & Liaoning & 0.288 \\
Hainan & 0.746 & Hunan & 0.505 & Guangdong & 0.275 \\
Jiangsu & 0.722 & Shanxi & 0.499 & Xinjiang & 0.170 \\
Tianjin & 0.664 & Guizhou & 0.483 & Qinghai & 0.166 \\
Anhui & 0.659 & Jilin & 0.476 & Yunnan & 0.153 \\
Chongqing & 0.647 & Inner Mongolia & 0.431 & Ningxia & 0.148 \\
Sichuan & 0.634 & Guangxi & 0.316 & Heilongjiang & 0.112 \\
Shaanxi & 0.585 & Xizang & 0.304 & & \\
Fujian & 0.576 & Henan & 0.298 & & \\
\hline
\end{tabular}

\section{Discussion}

\subsection{Built-Up Area Extraction}

Variable thresholds were used to extract urban pixels, with higher thresholds for economically advanced areas and lower thresholds for those less developed. The reasons were listed in the following context: (1) More developed regions in general had their built-up areas much brighter than less developed regions in the night-time because of their more dynamic socioeconomic activities at night and well-established urban infrastructure; (2) The non-urban outskirts of urban areas in developed regions were affected by the socioeconomic activities of their urban neighborhood and became much brighter than normal rural areas. This led to higher DN values in these areas, causing "over-glow" effects in the NTL image. The "over-glow" effect in an NTL image usually causes lit-up areas to appear larger than their real urban extent $[10,38]$. This is especially common in economically advanced areas; (3) More developed regions usually had denser road networks that could be lit up at night within and around built-up areas, which also contributed to the brightness of these pixels in the image.

The reform of the Chinese economy and boost of real estate market have also encouraged some land to be used for sports, tourism, and recreation purposes, such as golf courses, holiday villages, and other resorts that only partially light up or remain dark at night. However, most of these places are located in the outer suburbs and do not hold any legal development permissions, thus do not show on the national land purchase statistics records. Therefore, they will not result in longer time lags in data analysis and are not considered as built-up areas in this study.

With the economic boost in China, some families may own more than one house/flat, which causes some housing vacancy problems. Modern Chinese residential buildings are normally large, multi-level buildings that can house tens or hundreds of families. As long as certain numbers of owners/occupiers have moved into a building and keep their apartments lit up at night, there will be enough lights on to light up the building in the NTL imagery. Chinese people tend to live in the city center if they are given a choice. 
Buildings with higher vacancy rates are mainly at the edge of the city. The brightness of these areas is normally dimmer than the city center, but they are bright enough to be recorded by the NTL sensor at night and to be classified as built-up areas. For the above reasons, we believe that housing vacancies can only have a minor or no effect on the outcome of urban built-up area extraction.

\subsection{Land Development Time Lags and Developer Time Lags}

As described in Section 2, land development time lag consisted of developer time lag and consumer time lag. As consumer time lag was normally only a few months long, land development time lag could be approximated to developer time lag. Developer time lag should not be longer than land development time lag. However, the results in Section 3.2 had shown that six provinces/municipalities had land development time lags up to five years shorter than their developer time lags. These provinces were Zhejiang, Hubei, Fujian, Shandong, Henan, and Gansu.

The above false land development time lag results could be caused by various potential factors. Both Zhejiang and Hubei are more economically developed, but their NTL results showed zero development time lags, completely opposite to other developed regions in China. The developer time lags based on AHS statistical data were more reliable and more close to the land development time lags of other developed regions in China. These false results might have been caused by errors generated during NTL image processing procedures and over-glow effects. For the other four provinces, false results might be caused by effects of road construction, highway networks, or other human activities in these regions. Data from the National Bureau of Statistics had shown that Hubei, Shandong, and Gansu had a high rate of highway network construction in their economy in the last decade, which could impel a rapid growth in lit-up areas in the NTL image. Similarly, Henan had the most intensive highway network in China, of which the light from highways could be a disruption for extracting its built-up areas from DMSP/OLS data. In addition, the current method using NTL images mainly shows the expansion of the urban boundary, but overlooks the reconstruction of old urban areas.

The difference between land development time lag and developer time lag in about two-thirds of the provinces was one year or less, close to the average decorating and resting period. Therefore, we have high confidence that the NTL image data could be at least a relatively effective quantitative means of analyzing land banking and house hoarding behaviors of the real estate industry. It is possible to use it in quantitative study in this field with improved imaging processing techniques and means of validating the results.

\subsection{Real Estate Pricing, CREPI, and Time Lags}

As described in Sections 3.3 and 3.4, positive correlations were found between land development time lags and the rates of change in housing and land prices, as well as CREPI. Fluctuations of the rate of change in housing prices, land prices, and CREPI within each time lag group were obvious. This was probably caused by the approximation of the time lags because the time lags in this study were all set as integers. For example, a five-year time lag in a real situation might not be exactly five years but could be between 4.5 and 5.4 years. Meanwhile, the other three variables had exact values. 


\subsection{Maximum Profit—Common Driving Force behind Land Banking}

The results in Section 3.2 indicate that the length of development time lag periods was related to the economic situation of the provinces, with some exceptions. Developed areas such as Shanghai, Zhejiang, Beijing, Tianjin, Jiangsu, Hainan, etc. took a much longer time over land development. A prosperous economy, high resident income, and a large floating population in these areas had generated great demands in the real estate market and consequently attracted a tremendous amount of investment in the industry, especially from large listed domestic and foreign enterprises. According to Raymond [7], listed developers tend to devote more time and resources in land acquisition. They tend to take land as a tool for capital operation rather than just a means of production. They use the scale of land reservation as a symbol of company competitiveness to attracting investors to buy their stock. By postponing construction, they can achieve success in both the real estate market and the stock market. In a developed area, apart from listed developers, many property speculators are also hoarding land/properties in the real estate market. They do not buy properties for occupation but for reselling for profit in the future when the housing price reaches their expectation. Their behavior has also led to a large number of vacant houses, which prolonged the process of land development and caused longer development time lags in these areas. Developing regions such as Chongqing, Sichuan, Shaanxi, Hubei, Jiangxi, Guangxi, and Hunan experienced a rapid economic growth in the national economy during the study period. These regions also experienced a rapid land and housing price rise in the last decade, inevitably accompanied by land banking and house hoarding.

The results also showed land banking to be a common phenomenon in real estate development in China during the study period. The most common driving force behind this was a desire for maximum profit [42]. The developers are keen to buy land at a low price and build up and sell their development at the highest price they can get. When housing prices are below their expectations or when a significant potential rise in land or housing prices is predicted, developers will stock up on purchased lands until the market price reaches their expectation. On the one hand, land hoarding can be seen as "conserving" scarce land resources for later use to prevent cascading shortages in the future. Therefore, it is optimal for the society. On the other hand, land hoarding may lead to a shortage of land resources for new real estate development. In consequence, it may aggravate the imbalance between the supply and demand in the market and thus push up land and house prices even further. The rapid rise of land and housing prices in turn encourages more land banking. In some situations, although the development project has technically been completed, the developers can delay its completion and wait for bigger profits by slowing down the housing sales process. Barlow [43] noticed that in the real estate industry, skills in land purchasing and timing completions to maximize gains from house price inflation tend to be more important than the ability to compete through technical innovation. In addition, the uncertainty of future real estate prices also makes the decision to develop the land less immediately attractive [44].

It should also be emphasized that besides the pursuit of economic benefit by developers and speculators, there are other factors that can contribute to land development time lag. These factors are imperfect policies, unsuitable current urban infrastructure, changes of urban planning, and a number of other unpredictable factors that could affect the development process. These factors may have significant impacts in some specific regions. Maximum profit is the most common driving force behind land banking. 


\subsection{Uncertainty and Validation}

This is the first quantitative study on real estate development time lags in China. There are four major factors that may bring uncertainties to this study: (1) OLS sensors can degrade over time and affect data quality. Although three approaches have been taken in this study (see Section 2.4) to calibrate NTL data, they still may not yet fully address the differences between OLS sensors; (2) The IDP index recorded the freshly developed areas in each study site from the previous year. In the last few decades, alongside the urban residential and commercial building development, China has also largely improved its transport system by building up highways and high-speed rail systems and improving urban transport systems. Lit-up road networks and construction sites at night can contribute to the IDP index and create ambiguity in the results; (3) The IDP can capture the expansion of the urban areas; however, it is not sensitive to urban regeneration. Although the regeneration is almost negligible in comparison to the massive urban expansion, it may still cause uncertainty in the regional development difference results due to the large development gaps across the country; (4) Although NTL data is proven to be very useful for various urban studies including real estate development, its $1-\mathrm{km}^{2}$ spatial resolution is still too coarse for development that covers less than $1 \mathrm{~km}^{2}$ of land. This may lead to either under- or overestimation of a new development, depending on its brightness in the NTL image.

Currently, there were no official time-to-plan, time-to-built, time-to-sold records in China that could be used to compare to the study results. Therefore, validation analysis for this study is almost impossible. We hope in the future there may be some new statistical data source and very high-resolution remote sensing data available to carry out validation analysis for this type of research.

\section{Conclusions}

This paper presents a unique hybrid method that combined DMSP/OLS NTL image data with provincial real estate statistical data to estimate real estate development time lags at a provincial level in 31 provinces/municipalities of China. The results showed that real estate development time lag was common in China during 2000-2010. More than half of the study sites showed development time lags of three years or longer. A Comprehensive Real Estate Price Index (CREPI) was introduced to study whether the time lags were linked to local real estate markets. A strong and positive correlation was found between the real estate development time lags and CREPI values (with $r=0.619, n=31, p<0.0005$ ). The correlation was statistically significant. The results also showed that the time lag of real estate development is positively correlated to the activity of the local real estate market, the price trend of land and housing properties, and the local economic situation. The higher the rate of change in real estate housing/land prices is, the longer the time lag the real estate development project has, and the more severe the land banking problem is. Furthermore, this study concluded that developers' desire for maximum profit, government policies, unsuitable infrastructure, urban planning, ineffective laws, and government regulations can all have impacts on land hoarding. Maximum profit is the common driving force behind this phenomenon.

Along with the sustained rapid economic growth and significant boom in the Chinese real estate market, the large amount of vacant land caused by land hoarding has brought society a number of negative impacts. Extensive qualitative studies have been carried out on the presence, causes, damages, and potential countermeasures of the delay of land development; however, little has been done quantitatively. This 
study filled this gap by estimating the length of real estate development. The results can be used as a semi-quantitative reference for central and local governments to view the current situation in the real estate market and produce more effective policies and regulations to guide and manage the industry. This study has also proven that with the support of statistical data the DMSP/OLS NTL image could offer an economic, efficient, and reliable solution to estimate the time lag of real estate development and to compare and analyze its regional differences.

Due to data resolution and quality constraints, the results of this study are preliminary. We hope with the help of more detailed real estate statistics and the new NTL data captured by the Visible Infrared Imaging Radiometer Suite (VIIRS) of the National Polar Orbiting Environmental Satellite System (NPOESS) with onboard calibration and higher spatial resolution $\left(0.8 \mathrm{~km}^{2}\right)$, future studies can be carried out at a sub-provincial scale and produce more precise results on real estate development.

\section{Acknowledgments}

This study was supported by the Fundamental Research Funds for the Central Universities, and the Research Funds of Renmin University of China (10XNI008). The authors also sincerely thank the NOAA National Geophysical Data Centre for the DMSP/OLS NTL data; without this data support the above research would not have happened.

\section{Author Contributions}

In the process of research, each author has made a unique contribution. Wen Wang provided the main funding for the research and put forward the initial ideas and some useful suggestions. Li Zhang took responsibility for data analysis and writing papers. Ge Qu processed related data and wrote the draft.

\section{Conflicts of Interest}

The authors declare no conflict of interest.

\section{References}

1. Hui, E.C.M.; Liang, C.; Wang, Z.; Song, B.; Gu, Q. Real estate bubbles in China: A tale of two cities. Constr. Manag. Econ. 2012, 30, 951-961.

2. Chen, P. Mitigating Real Estate Presale Problems in China; University of Calgary: Calgary, AB, Cananda, 2007.

3. Zhang, H. Effects of urban land supply policy on real estate in China: An econometric analysis. J. Real Estate Lit. 2008, 16, 55-72.

4. Zhu, H.B. Analysis of the reason, harm and countermeasure of real estate developer regrating land. Guangdong Land Sci. 2011, 10, 45-48 (In Chinese).

5. White, P. Land availability, land banking and the price of land for housing: A review of recent debates. Land Dev. Stud. 1986, 3, 101-111.

6. Keuschnigg, C.; Nielsen, S.B. Housing markets and vacant land. J. Econ. Dyn. Control 1996, 20, 1731-1762. 
7. Raymond, Y.C. Housing price, land supply and revenue from land sales. Urban Stud. 1998, 35, 1377-1392.

8. Clapp, J.M.; Bardos, K.S.; Wong, S.K. Empirical estimation of the option premium for residential redevelopment. Reg. Sci. Urban Econ. 2012, 42, 240-256.

9. Wang, W.; Cheng, H; Zhang, L. Poverty assessment using DMSP/OLS night-time light satellite imagery at a provincial scale in China. Adv. Space Res. 2012, 49, 1253-1264.

10. Doll, C.N. CIESIN Thematic Guide to Night-time Light Remote Sensing and its Applications; Center for International Earth Science Information Network of Columbia University: Palisades, NY, USA, 2008.

11. Amaral, S.; Monteiro, A.M.; Câmara, G.; Quintanilha, J.A. DMSP/OLS night-time light imagery for urban population estimates in the Brazilian Amazon. Int. J. Remote Sens. 2006, 27, 855-870.

12. Elvidge, C.D.; Erwin, E.H.; Baugh, K.E.; Ziskin, D.; Tuttle, B.T.; Ghosh, T.; Sutton, P.C. Overview of DMSP nightime lights and future possibilities. In Proceedings of the 2009 IEEE Joint Urban Remote Sensing Event, Shanghai, China, 20-22 May 2009.

13. Lo, C.P. Modeling the population of China using DMSP operational linescan system nighttime data. Photo Gramm. Eng. Remote Sens. 2001, 67, 1037-1047.

14. Elvidge, C.D.; Ziskin, D.; Baugh, K.E.; Tuttle, B.T.; Ghosh, T.; Pank, D.W.; Erwin, E.H.; Zhizhin, W. A fifteen year record of global natural gas flaring derived from satellite data. Energies 2009, 2, 595-622.

15. Sutton, P.C.; Taylor, M.J.; Elvidge, C.D. Using DMSP OLS imagery to characterize urban populations in developed and developing countries. In Remote Sensing of Urban and Suburban Areas; Rashed, T., Jürgens C., Eds.; Springer: Berlin, Germany, 2010; pp. 329-348.

16. Roychowdhury, K.; Jones, S.D.; Arrowsmith, C.; Reinke, K. A comparison of high and low gain DMSP/OLS satellite images for the study of socio-economic metrics. IEEE J. Sel. Top. Appl. Earth Observ. Remote Sens. 2011, 4, 35-42.

17. Sutton, P.C. Modeling population density with night-time satellite imagery and GIS. Comput. Environ. Urban Syst. 1997, 21, 227-244.

18. Chand, T.K.; Badarinath, K.V.S.; Elvidge, C.D.; Tuttle, B.T. Spatial characterization of electrical power consumption patterns over India using temporal DMSP-OLS night-time satellite data. Int. J. Remote Sens. 2009, 30, 647-661.

19. Elvidge, C.D.; Baugh, K.E.; Kihn, E.A.; Kroehl H.W.; Davis E.R.; Davis C.W. Relation between satellite observed visible-near infrared emissions, population, economic activity and electric power consumption. Int. J. Remote Sens. 1997, 18, 1373-1379.

20. Gallaway, T.; Olsen, R.N.; Mitchell, D.M. The economics of global light pollution. Ecol. Econ. 2010, 69, 658-665.

21. Elvidge, C.D.; Hobson, V.R.; Baugh, K.E.; Dietz, J.B.; Shimabukuro, Y.E., Krug, T.; Krug, T.; Novo, E.M.L.M.; Echavarria, F.R. DMSP-OLS estimation of tropical forest area impacted by surface fires in Roraima, Brazil: 1995 versus 1998. Int. J. Remote Sens. 2001, 22, 2661-2673.

22. Chand, T.K.; Badarinath, K.V.S.; Murthy, M.S.R.; Rajshekhar, G.; Elvidge, C.D.; Tuttle, B.T. Active forest fire monitoring in Uttaranchal State, India using multi-temporal DMSP-OLS and MODIS data. Int. J. Remote Sens. 2007, 28, 2123-2132. 
23. Fuller, D.O.; Fulk, M. Comparison of NOAA-AVHRR and DMSP-OLS for operational fire monitoring in Kalimantan, Indonesia. Int. J. Remote Sens. 2000, 21, 181-187.

24. Standley, A.P. The use of coincident DMSP SSM/I and OLS satellite data to improve snow cover detection and discrimination. Int. J. Remote Sens. 1999, 20, 285-305.

25. Witmer, F.D.; O'Loughlin, J. Detecting the effects of wars in the Caucasus regions of Russia and Georgia using radiometrically normalized DMSP-OLS nighttime lights imagery. GISci. Remote Sens. 2011, 48, 478-500.

26. Croft, T.A. Nighttime images of the earth from space. Sci. Am. 1978, 239, 86-98.

27. Imhoff, M.L.; Stutzer, D.C.; Elvidge, C.D.; Lawrence, W.T. A technique for using composite DMSP/OLS "City Lights" satellite data to map urban area. Remote Sens. Environ. 1997, 61, 361-370.

28. Henderson, M.; Yeh, E.T.; Gong, P.; Elvidge, C.D.; Baugh, K. Validation of urban boundaries derived from global night-time satellite imagery. Int. J. Remote Sens. 2003, 24, 595-609.

29. Liu, Z.F.; He, C.Y.; Zhang, Q.F.; Huang, Q.X.; Yang, Y. Extracting the dynamics of urban expansion in China using DMSP-OLS nighttime light data from 1992 to 2008. Landsc. Urban Plan. 2012, 106, 62-72.

30. Yuan, T.; Zheng, X.Q.; Zhou, W. Analysis of territorial development intensity in China using DMSP/OLS data. In Proceedings of the IET International Conference on Smart and Sustainable City, Shanghai, China, 6-8 July 2011; pp. 227-232.

31. Yao, Y.L.; Li, Y. House vacancy at urban areas in China with nocturnal light data of DMSP-OLS. In Proceedings of the 2011 IEEE International Conference on Spatial Data Mining and Geographical Knowledge Services, Fuzhou, China, 29 June-1 July 2011; pp. 457-462.

32. Ma, T.; Zhou, C.H.; Pei, T.; Haynie, S.; Fan, J.F. Quantitative estimation of urbanization dynamics using time series of DMSP/OLS nighttime light data: A comparative case study from China's cities. Remote Sens. Environ. 2012, 124, 99-107.

33. Sutton, P.C. A scale-adjusted measure of "urban sprawl" using nighttime satellite imagery. Remote Sens. Environ. 2003, 86, 353-369.

34. Barth, J.R.; Lea, M.; Li, T. China's Housing Market: Is a Bubble About to Burst? Available online: http://dx.doi.org/10.2139/ssrn.2191087/ (accessed on 18 December 2012).

35. Guo, K.; Wang, J.; Shi, G.S.; Cao, X.H. Cluster analysis on city real estate market of China: Based on a new integrated method for time series clustering. Proc. Comput. Sci. 2012, 9, 1299-1305.

36. Zhuo, L.; Li, Q.; Shi, P.J.; Chen, J.; Zheng, J.; Li, X.; Wang, F. Characteristics analysis of urban land expansion in China in 1990s Using DMSP/OLS Data. Acta Sci. Nat. Univ. Sunyatseni 2007, 46, 98-102 (In Chinese).

37. He, C.Y.; Shi, P.Y.; Li, J.G.; Chen, J.; Pan, Y.Z.; Zhou, L.; Ichinose, T. Restoring urbanization process in China in the 1990s by using non-radiance calibrated DMSP/OLS nighttime lights imagery and statistical data. Chin. Sci. Bull. 2006, 51, 1614-1620.

38. Small, C.; Pozzi, F.; Elvidge, C.D. Spatial analysis of global urban extent from DMSP-OLS night lights. Remote Sens. Environ. 2005, 96, 277-291.

39. Shu, S.; Yu, B.L.; Wu. J.P.; Liu, H.X. Methods for deriving urban built up area using night light data: Assessment and application. Remote Sens. Technol. Appl. 2011, 26, 169-176 (In Chinese). 
40. Zhang, X.; Ge, Q.; Zheng, J. Relationships between climate change and vegetation in Beijing using remote sense data and phenologhical data. Acta Phytoecol. Sin. 2004, 28, 499-506 (In Chinese).

41. Van der Meer, F. Spectral curve shape matching with a continuum removed CCSM algorithm. Int. J. Remote Sens. 2000, 21, 3179-3185.

42. Wang, H.X.; Cai, M.H.; Shao, J.L. An analysis of property developers idle land based on real option theory. Areal Res. Dev. 2013, 32, 114-118 (In Chinese).

43. Barlow, J. Controlling the housing land market: Some examples from Europe. Urban Stud. 1993, 30, 1129-1149.

44. Titman, S. Urban land prices under uncertainty. Am. Econ. Rev. 1985, 75, 505-514.

(C) 2015 by the authors; licensee MDPI, Basel, Switzerland. This article is an open access article distributed under the terms and conditions of the Creative Commons Attribution license (http://creativecommons.org/licenses/by/4.0/). 